\title{
Pharmacogenetics in breast cancer: steps toward personalized medicine in breast cancer management
}

This article was published in the following Dove Press journal:

Pharmacogenomics and Personalized Medicine

15 September 2010

Number of times this article has been viewed

\author{
Sarah Rofaiel' \\ Esther N Muo' \\ Shaker A Mousa ${ }^{1,2}$ \\ 'The Pharmaceutical Research \\ Institute, Albany College of Pharmacy \\ and Health Sciences, Albany, \\ New York, USA; ${ }^{2}$ King Saud University, \\ Riyadh, Saudi Arabia
}

\begin{abstract}
There is wide individual variability in the pharmacokinetics, pharmacodynamics, and tolerance to anticancer drugs within the same ethnic group and even greater variability among different ethnicities. Pharmacogenomics (PG) has the potential to provide personalized therapy based on individual genetic variability in an effort to maximize efficacy and reduce adverse effects. The benefits of PG include improved therapeutic index, improved dose regimen, and selection of optimal types of drug for an individual or set of individuals. Advanced or metastatic breast cancer is typically treated with single or multiple combinations of chemotherapy regimens including anthracyclines, taxanes, antimetabolites, alkylating agents, platinum drugs, vinca alkaloids, and others. In this review, the PG of breast cancer therapeutics, including tamoxifen, which is the most widely used therapeutic for the treatment of hormone-dependent breast cancer, is reviewed. The pharmacological activity of tamoxifen depends on its conversion by cytochrome P450 2D6 (CYP2D6) to its abundant active metabolite, endoxifen. Patients with reduced CYP2D6 activity, as a result of either their genotype or induction by the coadministration of other drugs that inhibit CYP2D6 function, produce little endoxifen and hence derive limited therapeutic benefit from tamoxifen; the same can be said about the different classes of therapeutics in breast cancer. PG studies of breast cancer therapeutics should provide patients with breast cancer with optimal and personalized therapy.
\end{abstract}

Keywords: pharmacogenomics, genetic, pharmacokinetic, pharmacodynamic, personalized medicine, pharmacotherapy, anticancer drugs, efficacy, safety

\section{Introduction}

Breast cancer is the most common form of cancer and the second-leading cause of cancer-related death in women. ${ }^{1-3}$ It is estimated that there will be 192,370 new cases of breast cancer diagnosed in 2009 , accounting for $27 \%$ of all new cancer diagnoses. ${ }^{3}$ Certain heritable genetic factors may increase breast cancer risk, with susceptibility loci including high-penetrance genes that are rare (eg, BRCA1/2), as well as moderatepenetrance and low-penetrance genes and loci. Studies of these susceptibility loci have been critical to our understanding of the biological mechanisms of breast cancer. These studies have also been instrumental in shifting the focus in breast cancer research toward genetic and pharmacogenomic (PG) studies, in the hope that determination of individual genetic profiles in relation to these genes and loci will allow for targeted therapies to maximize therapeutic benefit.

Breast cancer is a heterogeneous disease, manifesting as different molecular subtypes, each of which responds to chemotherapeutic agents and radiation differently. ${ }^{2}$ Some of the currently available chemotherapy drugs for breast cancer management
Correspondence: Shaker A Mousa

The Pharmaceutical Research Institute, Albany College of Pharmacy and Health Sciences, One Discovery Dr Rensselaer, NY 12144, USA

Tel + I 5/8-694-7397

Fax + I 518-694-7567

Email shaker.mousa@acphs.edu 
include tamoxifen, aromatase inhibitors, fulverstrant, anthracyclines, taxanes, cyclophosphamide, vinorelbine, platinum, trastuzumab, lapatinib, bevacizumab, and others. Until very recently, the selection of treatment was almost exclusively based on the characteristics of the tumor, such as the presence of estrogen receptor (ER) or HER-2 receptor expression, with minimal emphasis on the patient's genetic make-up. ${ }^{4}$ The use of genomic profiles to assess the risk of tumor recurrence, drug resistance, and drug toxicity could be tremendously useful in breast cancer management. For instance, several studies have shown that patients with the cytochrome P450 enzyme 2D6 (CYP2D6)*4 allele, which causes a decrease in the enzymatic activity of CYP2D6, benefit less from tamoxifen therapy. Studies of aromatase inhibitors have shown that patients carrying a certain polymorphism in the aromatase gene may be at increased risk of osteoporosis. PG studies of breast cancer therapeutics can guide health care providers toward personalized medicine, providing patients with breast cancer with optimal individualized therapy. ${ }^{1-7}$

\section{PG and personalized medicine}

PG is the study of how genetic inheritance influences a person's response to drugs. ${ }^{5}$ Clinical observations of inherited differences in drug effects were first documented in the 1950s, giving rise to the field of pharmacogenetics and subsequently $\mathrm{PG} .{ }^{6} \mathrm{PG}$ uses genome-wide approaches to investigate the inherited basis of differences in drug responses in the interest of developing novel drugs and therapies. ${ }^{7}$ An understanding of the influence of genetics on efficacy or toxicity of a drug could potentially lead to the development of a personalized drug treatment algorithm based on an individual's genetic make-up. ${ }^{5,8,9}$ PG studies involve the application of molecular biology, high-throughput biotechnology, and bioinformatics in order to create customized drug treatments for a particular individual or patient population. ${ }^{10}$ The ultimate goal of PG is to customize drugs for a defined patient population so that the right drug is given at the right dose to the right person. In the future, the "onedrug-fits-all" approach to treating a particular disease and the "trial-and-error" approach to prescribing medications will be replaced by highly specific, "tailor-made" prescriptions based on the genetic makeup of an individual. ${ }^{5}$

\section{Single nucleotide polymorphisms}

The most common type of DNA variation in the human genome is the single nucleotide polymorphism (SNP). ${ }^{6}$ SNPs represent natural genetic variability in the human genome and are considered the major genetic source of phenotypic variability that differentiates individuals within a given species. They can occur in noncoding regions and in coding regions. The latter often generate polymorphic variation in expressed proteins, affecting their functional properties. If the SNP occurs in the promoter region of a gene, it may change the binding site for transcription factors and thus alter the regulation of expression. ${ }^{11}$ The allelic frequencies of a given SNP may be different in different populations. Because an SNP is present every 300-1,000 bases in man, there are several million possible nucleotide positions in the human genome at which there could be degrees of natural variation. ${ }^{12}$ It is believed that SNPs could be used to identify genes that contribute to population-wide, polygenic diseases. At present, information leading to a better understanding of genetic variability is an intense area of focus. The goal is to identify genes that contribute to disease, may be targets for new therapies, and may predict the outcome and side effects of a given therapy (Table 1). High-throughput technologies such as DNA microarrays are anticipated to serve as comprehensive tools for the development of accurate predictive genetic markers of treatment outcomes for many disease states. ${ }^{13}$ Health care providers should be prepared for a future in which these technologies will be used on a routine basis to optimize clinical outcomes.

\section{Genetic polymorphisms that influence the pharmacokinetics and pharmacodynamics of breast cancer therapeutics}

The field of pharmacogenetics initially focused only on drug metabolism, but now encompasses the spectrum of the drug delivery process, including transporters that influence drug absorption, distribution, and excretion. ${ }^{14}$ There are more than 30 families of drug-metabolizing enzymes in humans, all of which have genetic variants that may result in functional changes in the protein encoded. The study of polymorphisms in genes that encode drug-metabolizing enzymes, transporters, or targets can be used to predict the toxicity and response to pharmacologic agents that are used in breast cancer treatment. ${ }^{15}$ Transporter proteins have a significant role in regulating the absorption, distribution, and excretion of many of these pharmacologic agents. ${ }^{14}$ Members of the adenosine triphosphate (ATP)-binding cassette family of membrane transporters, for example, are among the most extensively studied transporters involved in drug transportation and 
Table I SNPs for key therapeutic classes in breast cancer

\begin{tabular}{|c|c|c|c|c|}
\hline Therapeutic class & Gene/polymorphism & PK application & Clinical outcomes & References \\
\hline \multicolumn{5}{|l|}{ Endocrine } \\
\hline \multirow[t]{9}{*}{ Tamoxifen } & CYP3A4*IB & $\begin{array}{l}\text { Increased CYP3A4 } \\
\text { expression }\end{array}$ & & 22 \\
\hline & CYP3A5*3C & & Possible association with improved RFS & 28 \\
\hline & SULTIAI*2 & $\begin{array}{l}\text { Decreased enzyme } \\
\text { activity }\end{array}$ & Possible association with increased ROD & 32 \\
\hline & SULTIAI*I & & Possible association with decreased ROR & 33 \\
\hline & UGT2BI5*2 & & $\begin{array}{l}\text { Possible association with decreased 5-year } \\
\text { survival rates }\end{array}$ & 28 \\
\hline & CYP2D $6 * 3 / * 4 / * 5 / * 6$ & Poor Metabolizers & $\begin{array}{l}\text { CYP2D6*4 possible association with worse } \\
\text { RFT, RFS, and BCR }\end{array}$ & 5,36 \\
\hline & CYP2D6*10/*17/*4| & $\begin{array}{l}\text { Intermediate } \\
\text { metabolizers }\end{array}$ & $\begin{array}{l}\text { CY2D6*10/*4I possible association with } \\
\text { worse RFT, ROR, and BCR }\end{array}$ & 26 \\
\hline & ER d5 & Loss of exon 5 & $\begin{array}{l}\text { Possible association with tamoxifen } \\
\text { therapy failure }\end{array}$ & 40 \\
\hline & CCNDI/PAKI & Over-expression & $\begin{array}{l}\text { Possible association with shorter RFS; } \\
\text { PAKI also may reduce benefit of } \\
\text { tamoxifen }\end{array}$ & $4 \mathrm{I}, 42$ \\
\hline \multicolumn{5}{|c|}{ Aromatase inhibitors } \\
\hline & CYPI9AI polymorphisms & & & $50-54$ \\
\hline & $\begin{array}{l}\text { Cys264, Thr364, } \\
\text { *Arg39Cys264 }\end{array}$ & $\begin{array}{l}\text { Decreased enzyme } \\
\text { activity }\end{array}$ & $\begin{array}{l}\text { Possible association with letrozole } \\
\text { resistance }\end{array}$ & 45 \\
\hline & rs4646 & & Possible association with increased & 50 \\
\hline & & & TTP and letrozole response & \\
\hline & CYPI9AI(I53IC>T) & & Possible association to osteoporosis & 52,53 \\
\hline \multicolumn{5}{|c|}{ Chemotherapy agents } \\
\hline Taxanes & CYPIBI*3 & & $\begin{array}{l}\text { Possible association with better PFS } \\
\text { and better complete response }\end{array}$ & 64,66 \\
\hline Vinorelbine & $\begin{array}{l}\text { ABCBI } 3435 \text { C }>\text { T, } \\
\text { CYP2D } 6 * 4, \text { CYP } 3 A P * 3, \\
\text { CYP3A5*3 }\end{array}$ & & $\begin{array}{l}\text { Possible association with vinorelbine } \\
\text { response }\end{array}$ & 70,71 \\
\hline \multirow[t]{3}{*}{ Cyclophosphamide } & CYP3A4*IB, *CYP3A5*I & & $\begin{array}{l}\text { Possible association with survival and } \\
\text { ovarian failure }\end{array}$ & 77,78 \\
\hline & CYP2B6*6 & $\begin{array}{l}\text { Higher clearance and } \\
\text { shorter half-life of } \\
\text { cyclophosphamide }\end{array}$ & & 81 \\
\hline & $\begin{array}{l}\text { CYP2B6 }(-2320 \mathrm{C}>\mathrm{T} \\
-705 \mathrm{~T}>\mathrm{C}, 18492 \mathrm{C}>\mathrm{T})\end{array}$ & & Possible association with leukopenia & 80 \\
\hline \multicolumn{5}{|l|}{ Antimetabolites } \\
\hline & MTHFR I298 & Decreased enzyme activity & Possible association with poorer survival rate & 90 \\
\hline & MTHFR C677T & Decreased enzyme activity & Possible association with better survival time & 90,91 \\
\hline & TYMS TSER & & Association with survival & 93 \\
\hline \multicolumn{5}{|l|}{ Gemcitabine } \\
\hline & CDA A70T & $\begin{array}{l}\text { Decreased gemcitabine } \\
\text { clearance }\end{array}$ & Possible association with neutropenia & 84,85 \\
\hline & RRMI $(-37 \mathrm{C},-524 \mathrm{~T})$ & & $\begin{array}{l}\text { Possible association with better tumor } \\
\text { response, PFS, and OS }\end{array}$ & 86,87 \\
\hline \multicolumn{5}{|l|}{ Anthracyclines } \\
\hline \multirow[t]{3}{*}{ Doxorubicin } & CBR3 IIG $>A$ & & $\begin{array}{l}\text { Possible association with increased tumor } \\
\text { reduction and hematologic toxicity }\end{array}$ & 98 \\
\hline & $A B C B I 3435 T$ & & $\begin{array}{l}\text { Possible association with better } \\
\text { clinical response }\end{array}$ & 100,101 \\
\hline & SLC22A I 6 I46A $>G$ & $\begin{array}{l}\text { Increased exposure } \\
\text { to doxorubicin }\end{array}$ & & 99 \\
\hline Epirubicin & $\begin{array}{l}\text { NQOI } 556 \mathrm{C}>2 \\
\text { NQOI } * 2\end{array}$ & & $\begin{array}{l}\text { Possible association with drug response } \\
\text { and survival outcomes }\end{array}$ & 105 \\
\hline
\end{tabular}


Table I (Continued)

\begin{tabular}{|c|c|c|c|c|}
\hline Therapeutic class & Gene/polymorphism & PK application & Clinical outcomes & References \\
\hline \multicolumn{5}{|l|}{ Platinums } \\
\hline & GSTMI deletion & & $\begin{array}{l}\text { Possible association with increased } \\
\text { median survival time }\end{array}$ & $5,6,95$ \\
\hline & METIF G-7T & $\begin{array}{l}\text { Lower platinum } \\
\text { concentration }\end{array}$ & $\begin{array}{l}\text { Possible association with shorter } \\
\text { survival }\end{array}$ & 95 \\
\hline & ERCCI NII8N & & $\begin{array}{l}\text { Possible association with median } \\
\text { survival time and TTP }\end{array}$ & $5,6,95$ \\
\hline \multicolumn{5}{|l|}{ Targeted therapy } \\
\hline Trastuzumab & $\begin{array}{l}\text { Fc- } \gamma \text { RIIIA-I58 V/V, } \\
\text { Fc- } \gamma \text { RIla- }|3| \mathrm{H} / \mathrm{H}\end{array}$ & & $\begin{array}{l}\text { Possible association with objective } \\
\text { response rate and PFS }\end{array}$ & 107 \\
\hline
\end{tabular}

Note: *indicates CYP allele.

Abbreviations: PK, pharmacokinetic; MTHFR, methylenetetrahydrofolate reductase; RFS, recurrence free survival; ROD, rise of death; ROR, risk of relapse; RFT, relapse free time; BCR, breast cancer relapse; TTP, time to progression; PFS, progression free survival; OS, overall survival.

distribution. P-glycoprotein, a specific member of the ATP-binding cassette family, is encoded by $A B C B 1$, also known as $M D R 1 .{ }^{16}$ The function of P-glycoprotein is the energy-dependent cellular efflux of substrates. Bilirubin, anticancer agents, cardiac glycosides, immunosuppressive agents, glucocorticoids, human immunodeficiency virus (HIV) type 1 protease inhibitors, and many other medications have been shown to be targets of P-glycoprotein. The expression of P-glycoprotein in many normal tissues suggests that it has a physiological role in the excretion of xenobiotics and metabolites into urine, bile, and the intestinal lumen. Of course, transportation is only one part of the full spectrum of drug delivery, albeit a crucial one. A better understanding of how polymorphisms in genes encoding transporters, metabolizing enzymes, and receptors affect drug efficacy and toxicity is an important step toward making the clinical practice of pharmacogenetics a reality.

\section{Cancer therapeutics}

This section will discuss the classes of drugs currently used in the treatment of breast cancer, including their pharmacokinetic (PK) and pharmacodynamic (PD) properties, and SNPs that influence the uptake and metabolism of the drugs, as well as drug response and clinical outcomes associated with specific SNPs.

\section{Hormonal/endocrine therapies Tamoxifen}

Tamoxifen binds selectively to estrogen receptors (ERs) and is, therefore, indicated for patients who express ER and whose tumors are endocrine-sensitive. It has been extensively used in patients with breast cancer for the last 30 years. ${ }^{9}$

Tamoxifen is a prodrug that is metabolized by members of the cytochrome (CYP) P450 family into 2 active metabolites: 4-hydroxy tamoxifen (4OH-TAM) and 4-hydroxyl-Ndesmethyl-tamoxifen (endoxifen). CYP3A4/5 is responsible for the conversion of tamoxifen into N-desmethyl-tamoxifen, which is then converted into its active metabolite, endoxifen, by CYP2D6. CYP2D6 is also responsible for the conversion of tamoxifen into 4OH-TAM. The active metabolites of tamoxifen then undergo sulfation via sulfotransferase (SULT1A1) and glucoronidation via uridine diphosphate (UDP)-glucuronosyltransferase (UGT2B15) leading to excretion. ${ }^{17,18}$

The accepted dose of tamoxifen is $20 \mathrm{mg} / \mathrm{d}$. However, in a recent study of steady-state levels of tamoxifen and active tamoxifen metabolites, there was interpatient variability for all 3 metabolites. ${ }^{9}$ These results suggest that the general recommended dose of tamoxifen may not be optimal for all patients and hence PK monitoring might be of great value.

An additional consideration for tamoxifen treatment is that hot flashes, a common side effect of tamoxifen therapy, occur in $50 \%-70 \%$ of patients treated with tamoxifen. It is not possible to simply treat these hot flashes with exogenous estrogen. However, it has been found that some patients respond to selective serotonin reuptake inhibitors (SSRIs), which inhibit CYP2D6. ${ }^{19,20}$ Thus, concomitant administration of CYP2D6 inhibitors, like the aforementioned SSRIs, may affect breast cancer outcomes with tamoxifen therapy through conversion of a potent metabolizer to a phenotypically poor metabolizer (PM). Examples of potent CYP2D6 inhibitors include the antidepressants fluoxetine, paroxetine, and venlafaxine; moderate or weak inhibitors include cimetidine, amiodarone, ticlopidine, and haloperidol. ${ }^{19}$ There is also the possibility that other CYP isoforms such as CYP2C19 might potentially catalyze the formation of tamoxifen metabolites beyond those generated by CYP2D6. ${ }^{21}$ 


\section{Related SNPs CYP3A4}

CYP3A4 is involved in the metabolism of over $60 \%$ of currently used chemotherapy drugs. Therefore, it plays a significant role in clinical settings. A common SNP of CYP3A4 is CYP3A4*1B $(-392 \mathrm{~A}>\mathrm{G})$, which is associated with increased CYP3A4 expression. However, to date, the clinical significance of CYP3A4 polymorphisms is unknown. ${ }^{22}$

\section{CYP3A5}

The most common variant of CYP3A5 is CYP3A5*3C (IVS3-327A $>$ G, 6986A $>$ G). This polymorphism results in a splicing defect and an absence of CYP3A5 protein. ${ }^{23,24}$ Three separate studies have failed to show any association between CYP3A5*3C and tamoxifen metabolism or clinical outcomes. ${ }^{25-27}$ However, in a study involving 677 patients with postmenopausal breast cancer randomized to either 2 or 5 years of tamoxifen, it was found that patients in the 5-year treatment group who were homozygous for CYP3A $5 * 3$ had significantly improved recurrence-free survival $(P=0.002)$. CYP3A5*3 homozygous patients in the 2-year treatment group showed an increased risk of recurrence, but this was not statistically significant $(P=0.15) .{ }^{28}$ These results justify progression to large population studies of relevant clinical outcomes associated with this SNP.

\section{SULTIAI}

Three polymorphisms in SULT1A1 have been identified: SULT1A1*1, SULT1A1*2, and SULT1A1*3. The most common polymorphism, SULT $1 \mathrm{~A} 1 * 2$, results in decreased enzymatic activity of SULT1A1 due to a shorter protein half-life. The effect is decreased sulfation of 4OH-TAM. ${ }^{29-31}$ The clinical relevance of SULT1A1*2 was investigated in a study including 337 patients with breast cancer receiving tamoxifen therapy. Patients who were homozygous for SULT1 A $1 * 2$ had an almost a 3-fold increase in risk of death as compared to patients who had a common allele or who were heterozygous (SULT1A1*1/ SULT1A $1 * 2) .{ }^{32}$ A separate study involving 226 patients with breast cancer found that individuals who were homozygous for SULT1A1*1 had a decreased risk of recurrence..$^{33} \mathrm{~A}$ subsequent study, however, found no association between SULT1A1 polymorphisms and tamoxifen or its metabolites. ${ }^{26}$ Copy number variation might be more important for functional variations in SULT1A1 activity than nonsynonymous SNPs. ${ }^{34}$
UGT2BI5

UGT2B15*2(253G $>$ T; D85Y) is a nonsynonomous polymorphism of UGT2B15. A 2005 retrospective study involving 165 patients analyzed SULT1A1, UGT2B15, and CYP2D6 polymorphisms. The study found that patients carrying the SULT1A1*2 variant and at least one UGT2B15 allele had significantly reduced 5-year survival rates. ${ }^{35}$ However, another study looking at the association of UGT2B15*2 with tamoxifen and clinical outcomes found no association. ${ }^{28}$

\section{CYP2D6}

More than 80 allelic variants of CYP2D6 have been identified and grouped into 4 categories: poor, intermediate, extensive, and ultra-rapid metabolizers. ${ }^{5}$ Poor metabolizers (PMs) are subjects who have inactive enzyme, deletion of the CYP2D6 gene, or loss of functional alleles of CYP2D6. The nonfunctional variants of CYP2D6 are CYP2D6*3, CYP2D6*4, and CYP2D6*6; enzyme is absent in carriers of the CYP2D $6 * 5$ variant.

CYP2D6 SNPs represent a good example of populationbased variations in SNP frequency. Five to $10 \%$ of Caucasians are PMs, with the CYP2D6*4 allele present in $70 \%-90 \%$ of the population, while this allele is rare in Asians and black Africans. ${ }^{5}$ In Asians, the CYP2D6*10 allele is a major polymorphism, resulting in an intermediate metabolizer (IM) phenotype. This phenotype is present in $38 \%-70 \%$ of Asians and $20 \%-34 \%$ of Africans, but is rare in Caucasians. Individuals with an IM phenotype have somewhat reduced in vitro activity of CYP2D6 enzymes. ${ }^{5}$

In contrast to PMs and IMs, ultra-rapid metabolizers carry gene duplications or multiduplications that result in increased enzymatic activity. Variant alleles in this category include CYP2D6*2XN, CYP3A4*1B, and CYP3A5*3. These variants are rare in Caucasians and Asians, but common in Ethiopians and Saudi Arabians. The identification of ultra-rapid metabolizers may help in the selection of patients who will benefit from a longer period of tamoxifen use (up to $4-5$ years) before switching to aromatase inhibitors.

The enzymes responsible for elimination and inactivation of tamoxifen and its metabolites through conjugation with either a sulfate or a glucuronide may also have important genetic variations. To date, however, studies have yielded conflicting data on the relationship between these variations and tamoxifen processing, highlighting the need for further studies. ${ }^{5}$

CYP2D6 SNPs have been well characterized. A recent study investigating the CYP2D6*4 allele, a PM that is 
common in Caucasians, in patients being treated with tamoxifen found that individuals who were homozygous for CYP2D6*4 had significantly lower endoxifen levels than patients who had the wild-type gene; patients who were heterozygous for CYP2D6*3/*4/*5/*6 had intermediate levels of endoxifen. ${ }^{26}$ Clinical outcomes in relation to CYP2D6*4 have also been investigated. An early study showed that patients with decreased levels of metabolism of tamoxifen had a significantly decreased time to recurrence $(P=0.034)$, worse relapse-free survival $(P=0.017)$, and a significantly higher risk of breast cancer relapse $(P=0.007)$ as compared with patients who had normal levels of metabolism. ${ }^{36}$ The results of this study were confirmed in 2 subsequent studies of patients who were homozygous for CYP2D6*4. The first study included 190 patients with postmenopausal breast cancer treated with adjuvant tamoxifen. Women who were homozygous for CYP2D6*4 had significantly lower relapse-free and disease-free survival (DFS) and had a lower incidence of hot flashes as compared with women either with one or no CYP2D6*4 alleles. ${ }^{37}$ The second study corroborated these results, demonstrating that homozygous patients receiving tamoxifen had a shorter relapse-free time and reduced DFS than patients with at least one wild-type CYP2D6 allele. However, no association with overall survival was found in this or a subsequent study of 162 patients with breast cancer. ${ }^{25,35}$ A related study of 226 patients with breast cancer demonstrated significantly improved survival in patients carrying CYP2D6*4 and SULT1A1*1 (wild-type) alleles. ${ }^{33}$ Finally, a study involving 486 patients with breast cancer found that carriers of the CYP2D6 alleles *4, *5, *10, and $* 41$ had a reduced relapse-free period $(P=0.02)$, poorer event-free survival $(P=0.02)$, and significantly increased recurrence. ${ }^{21}$ Overall, these results indicate that genotyping of patients with impaired CYP2D6 function may be beneficial in a clinical setting to determine which patients will derive the most benefit from adjuvant tamoxifen therapy.

\section{$\mathrm{ESR} 1 / \mathrm{ESR} 2$}

ESR1/ESR2 encodes the target of tamoxifen, the ER. In a study of the occurrence and frequency of the exon 5 deletion variant (ER d5) of ESR 1/2, the d5 variant was detected in both breast tumor tissue and normal tissue, indicating it is a naturally occurring polymorphism. Patients who relapsed within the first 15 months had increased levels of expression of $\mathrm{d} 5$ as compared with those who did not, indicating that increased ER d5 expression may result in relapse due to clonal expansion of tamoxifen-resistant tumor cells. ${ }^{38}$

\section{CCNDI and PAKI}

Cyclin D1 (CCND1) and p21-activated kinase 1 (PAK1) have been implicated in the activation of ER expression. Jirstrom et $\mathrm{al}^{39}$ found that over expression of CCND1 is associated with an increased risk of breast cancer recurrence and inversely linked to overall survival. ${ }^{39}$ Another study investigating both CCND1 and PAK1 found an association between amplification of either one of these genes and shorter recurrence-free survival $(P=0.025)$. Reduced benefit from the drug was also demonstrated in patients with PAK1, but not CCND1 amplification. ${ }^{40}$ Similarly, Lundgren et $\mathrm{a}^{41}$ demonstrated that amplification of CCND1 and PAK1 may be associated with tamoxifen response.

\section{TP53}

TP53 encodes p53, an important tumor suppressor that induces apoptosis. Wegman et $\mathrm{al}^{42}$ examined the P72 $(215 \mathrm{C}>\mathrm{G})$ SNP of TP53 and found that patients who had at least one TP53 codon 72 proline allele had a significantly better response to tamoxifen. ${ }^{42}$ Studies have also shown that the over expression of p53 is associated with poorer clinical outcomes and resistance to tamoxifen in premenopausal women with breast cancer. ${ }^{43}$

\section{Aromatase inhibitors}

Aromatase inhibitors have proven efficacy in both advanced and early postmenopausal hormone receptor positive breast cancers. The predominant problem associated with aromatase inhibitors is musculoskeletal complaints reported by some users. This side effect can be debilitating and has led to discontinuation of aromatase inhibitor therapy in some cases. This difference in clinical response has prompted researchers to take a second look to see if there are pharmacogenetic differences among patients that might enable the identification of cases in which aromatase inhibitor therapy would be appropriate and safe. ${ }^{44,45}$

Aromatase inhibitors inhibit the formation of estrogen in breast tissue and are used in advanced disease settings after 5 years of tamoxifen therapy. ${ }^{5}$ The target of aromatase inhibitors is the CYP enzyme aromatase, which is encoded by $C Y P 19 A 1$, also known as the aromatase gene. Aromatase inhibitors work by blocking the conversion of androstenedione and testosterone to estrone and estrodiol in the periphery. As such, they are used in postmenopausal women since they will have no effect on the ovaries. Aromatase inhibitors can be classified into 2 groups: steroidal (exemestane) and nonsteroidal (letrozole and anastrazole), reducing crossresistance between therapies and allowing prolonged use of 
different inhibitors. The side effects of aromatase inhibitors are usually less severe and less frequent than tamoxifen. ${ }^{46}$

\section{Related SNPs CYPI9AI}

More than 88 CYP19A polymorphisms have been identified, resulting in 44 haplotypes that vary widely among ethnic groups. A survey of 60 patients of Caucasian, African-American, Han Chinese American, and Mexican American ethnicity found that Cys264, Thr364, and doublevariant Arg39Cys264 allozymes had significantly decreased activity as compared with the wild-type enzyme. The Arg39Cys264 allozyme also exhibited a significantly increased inhibitor constant for letrozole. The frequencies of the Arg39 and Cys264 alleles varies among ethnic groups, with Cys264 occurring at a higher frequency in Han Chinese Americans (11.7\%) and African-Americans (22.5\%) as compared with Caucasian Americans (2.5\%) and Mexican Americans (5\%). The Arg39 variant was shown to be present at a frequency of $6.7 \%$ in Han Chinese Americans, but was rare in other ethnic groups. These results suggest that patients with decreased enzyme activity may not receive the full benefit of aromatase inhibitors. ${ }^{47}$

Two separate Spanish studies examined the rs 4646 polymorphism of CYP19A1. The first study including 67 patients with postmenopausal breast cancer receiving letrozole found that patients with the rs 4646 polymorphism had an increased complete response rate and time to progression..$^{48}$ The second study including 94 patients also receiving letrozole therapy found that 8 polymorphisms, one of which included rs 4646 , could predict response to letrozole with $86 \%$ accuracy at 4 months. ${ }^{49}$

CYP19A1 has also been linked to bone homeostasis in postmenopausal women. One of the major side effects of aromatase inhibitors is bone loss and fractures. Several studies have been conducted examining the relationship between aromatase inhibitors and CYP19A1 and bone homeostasis. One study, involving 286 postmenopausal patients, found that a polymorphism in the 3 -untranslated region of CYP19A1 (1531C $>\mathrm{T}$ ) was linked to osteoporosis in women $>60$ years of age. There were 6 other polymorphisms, however, that showed the same association, so the contribution of CYP191A alleles to osteoporosis remains unclear. $^{50,51}$ Another study examining polymorphisms in CYP19A found that postmenopausal women who had a biallelic polymorphism in the $5^{\prime}$-untranslated region of CYP19A1 had decreased spine and hip bone mineral density. This genotype was also associated with a higher prevalence of vertebral fractures $(P=0.03) .{ }^{52}$ Additional studies are needed to help identify which patients may be at higher risk for developing osteoporosis when taking aromatase inhibitors.

\section{Fulverstrant}

Fulverstrant is a pure antiestrogen that antagonizes the hormone-dependent activation of ER. It is glucuronidated by UGT1A1, UGT1A3, UGT1A4, and UGT1A8. There is a paucity of data in the literature regarding clinical outcomes associated with UGT polymorphisms and fulverstrant, emphasizing the need for more research in this area. ${ }^{53}$

\section{Chemotherapeutics}

\section{Taxanes}

Taxanes stabilize normally dynamic microtubules by binding to sites on tubulin dimers, and its cell cytotoxic effects result from inhibition of cell division. Taxanes, including paclitaxel and docetaxel, are typically used in combination with other chemotherapy agents such as anthracyclines. ${ }^{54}$

Paclitaxel and docetaxel are substrates of P-glycoprotein located in the biliary canalicular membrane. Docetaxel is primarily metabolized by CYP3A4/5, whereas paclitaxel is metabolized by CYP2C8/CYP3A4. Metabolism in both cases results in inactive hydroxylated metabolites. ${ }^{34}$ Docetaxel and paclitaxel can be bound by a plasma protein known as $\alpha 1$-acid glycoprotein, which is encoded by the ORM1 and ORM2 genes. These genes have been shown to be associated with taxane clearance. ${ }^{55}$ High interpatient variability in ORM expression levels have been related to clinical response to taxane. ${ }^{56,57}$ These variations in $O R M$ expression levels are most likely due to changes in ORM plasma levels in response to inflammation. Various other physiological and pathological states have been suggested as mechanisms of regulation of ORM expression. ${ }^{58}$

\section{Related SNPs CYPIBI}

CYP1B1 is the most well-known cytochrome in breast cancer tissue and is usually found in abundance in tumor cells..$^{59-61}$ The CYP1B1*3 polymorphism has been proposed as an indicator for progression-free survival in patients with breast cancer. For example, in a study of 93 patients with breast cancer, Marsh et al ${ }^{62}$ demonstrated an association between CYP1B1*3 and survival in patients with breast cancer. In a study involving 89 patients with breast cancer being treated with paclitaxel and doxorubicin, a 21-gene signature was identified that corresponded significantly 
with a complete response. ${ }^{63}$ The same 21 -gene signature corresponded significantly with a complete response in a separate study of 97 patients with breast cancer treated with docetaxel. ${ }^{64}$ This gene signature, known as the Oncotype Dx panel, may help predict response to taxane therapy, potentially allowing the identification of patients who would not benefit from this type of treatment.

\section{Vinorelbine}

Vinorelbine is a semisynthetic vinca alkaloid that inhibits DNA replication by disrupting microtubule assembly. It is usually used in advanced breast cancer, especially in patients who have failed anthracycline and taxane therapy. ${ }^{5,65}$ Pharmacogenetic studies of vinorelbine are limited. Metabolism occurs principally by way of CYP3A4, and resistance is believed to be mediated by ABCB 1.5

\section{Related SNPs}

\section{$A B C B I$ and CYP3A}

A polymorphism of ABCB1 (ABCB1 3435C $>$ T) was associated with response to vinorelbine-cisplatin therapy among a group of 69 Han Chinese patients with non-small cell lung cancer. ${ }^{66}$ In a separate study, several CYP polymorphisms, including 2 in CYP3A, were associated with response to vinorelbine-based therapy in a group of 59 Chinese patients with non-small cell lung cancer. ${ }^{67}$ Another study involving mostly Caucasian patients reported no association between polymorphisms in CYP3A or ABCB1 and response to vinorelbine therapy. ${ }^{68}$ These results were confirmed by Schott et al ${ }^{69}$ who showed that in 25 patients with breast cancer; there was no association between CYP3A5 polymorphisms and vinorelbine clearance or toxicity. Additional studies of the PG of vinorelbine in breast cancer therapy are needed.

\section{Cyclophosphamide}

Cyclophosphamide is an alkylating agent that is commonly used in combination therapy to treat breast cancer. Cyclophosphamide is metabolized into phosphoramide mustard and acrolein. Phosphoramide mustard is an active DNA crosslinking metabolite. ${ }^{70}$ An early study of cyclophosphamide PK in 14 patients with breast cancer reported that there was 54\% interindividual variation in central volume of distribution among 14 patients with breast cancer. In the same study, there was $22 \%$ interindividual variability in clearance of the cyclophosphamide metabolite 4-0-hydroxycyclophosphamide. ${ }^{71}$ It is believed that both body weight and age have an impact on cyclophosphamide $\mathrm{PK}$, with younger patients having a faster cyclophosphamide half-life. ${ }^{72,73}$ The PG of cyclophosphamide have not been studied extensively because it is commonly used in combination with other chemotherapeutic agents. ${ }^{74}$

\section{Related SNPs CYP3A}

A recent prospective cohort study was performed including 127 patients with premenopausal early-stage breast cancer. The purpose of the study was to determine whether there was an association between polymorphisms of cyclophosphamide metabolizing enzymes and risk of ovarian failure after adjuvant chemotherapy. Patients who were less than 45 years of age and carried the CYP3A4*1B allele had a significantly longer time to reach chemotherapy-related ovarian failure. ${ }^{75}$ In another study involving 85 patients with breast cancer, the CYP3A $4 * 1 \mathrm{~B}$ or CYP3A $5 * 1$ polymorphism was associated with survival and increased cyclophosphamide plasma area under the time curve, which is an indicator of poor metabolism. ${ }^{76}$

\section{CYP2B6}

CYP2B6 is involved in the activation of cyclophosphamide. ${ }^{77}$ The CYP2B6*6 polymorphism was linked to higher clearance and shorter cyclophosphamide half-life in a study of 103 Japanese patients with cancer (lymphoma or breast cancer). Other polymorphisms of CYP2B6 (-2320C $>\mathrm{T}$; $-705 \mathrm{~T}>\mathrm{C} ; 18492 \mathrm{C}>\mathrm{T}$ ) were associated with leucopenia. However, in this same study, there was no association between cyclophosphamide PK and CYP3A polymorphisms. ${ }^{78}$ These results were corroborated by a recent study in 124 Caucasians, which demonstrated no association between CYP3A or CYP2B6 polymorphisms and cyclophosphamide PK. ${ }^{79}$ The Petros Study also failed to demonstrate an association with CYP2B6 polymorphisms. ${ }^{76}$ Additional studies are needed to better understand the link between CYP2B6 polymorphisms and response to cyclophosphamide therapy.

\section{Gemcitabine}

Gemcitabine is a nucleoside analog that is transported into cells by the transporters SLC28 and SLC29. It is then converted by deoxycytidine kinase (DCK) into the active metabolites gemcitabine diphosphate and gemcitabine triphosphate. Gemcitabine diphosphate inhibits thymidylate ribonucleotide reductases (RRM1 and RRM2), which generate the nucleotides required for DNA synthesis and repair. The decrease in available nucleotides results in the incorporation of gemcitabine triphosphate into the DNA, resulting in strong inhibition of DNA synthesis and repair. $^{80,81}$ 


\section{Cytidine deaminase}

Gemcitabine is inactivated by cytidine deaminase (CDA). In a study involving 256 Asian patients with cancer, the nonsynonymous CDA A70T polymorphism was associated with reduced gemcitabine clearance and increased incidence of severe neutropenia in patients taking a combination of gemcitabine with cisplain, carboplatin, or 5-flurouracil (5-FU). ${ }^{82}$ This particular CDA variant is more common in Africans than in Japanese or Europeans $(13 \%$ vs $4.3 \%$ vs $0 \%) .{ }^{83}$

\section{RRMI}

Variants in RRM1 (2455A $>$ G and 2464G $>$ A) have been associated with a significant reduction in incidence of neutropenia in patients receiving gemcitabine alone. RRMI polymorphisms have also been linked to decreased use of granulocyte colonystimulating factor and poorer progression-free survival and overall survival outcomes. ${ }^{84} \mathrm{~A}$ retrospective study of patients with advanced stage breast cancer who were being treated with gemcitabine/carboplatin found that the $-37 \mathrm{C}$ and $-524 \mathrm{~T}$ RRM1 polymorphisms were associated with better tumor response, progression-free survival, and overall survival. ${ }^{85}$

\section{Deoxycytidine kinase (DCK)}

Variants in DCK, the rate-limiting activating enzyme in the gemcitabine pathway, have been identified, but further studies are needed to determine the relationship between these variations and response to gemcitabine in patients with breast cancer. ${ }^{86}$

\section{Capecitabine/5-FU}

Capecitabine is an oral prodrug of fluorouracil (5-FU). Variations in thymidylate synthetase (TS), the principal target of 5-FU, methylenetetrahydrofolate reductase (MTHFR), a key regulatory enzyme in folate metabolism, and dihydropyrimidine dehydrogenase, which catabolizes 5-FU, might potentially contribute to interindividual variability in patient responses to 5-FU-based therapeutic management. ${ }^{87}$

\section{Related SNPs}

\section{MTHFR and TS}

Two common polymorphisms of MTHFR, C677T and A1298C, result in decreased enzyme activity and chemosensitivity of tumor cells. In a study of 248 African-American and Caucasian patients with breast cancer, the presence of a 1298 variant $(\mathrm{A} / \mathrm{C}$ or $\mathrm{C} / \mathrm{C})$ was associated with decreased survival rate. The opposite effect was observed in patients with variant alleles at codon $677(\mathrm{C} / \mathrm{T}$ or T/T); however, this result was not statistically significant. In addition, the authors noted that these results were affected by race and ethnicity ${ }^{88} \mathrm{~A}$ separate study including 1,067 Asian patients with breast cancer found that MTHR $677 \mathrm{C}>\mathrm{T}$ was associated with increased risk of death. ${ }^{89}$

Variable copy number of a 28-basepair tandem repeated sequence (TSER*2, TSER*3, TSER*4, TSER*, and TSER $*$ ) in the TS enhancer region has been associated with increased TS expression and significantly poorer response to treatment. ${ }^{5}$ TSER $* 2$ and TSER $* 3$ are the predominant alleles in most populations..$^{90}$ The TS TSER polymorphism was associated with survival in a small population of patients with breast cancer (35 patient's total). In contrast, a larger study of 93 patients receiving 5-FU and methotrexate found no association between MTHFR or TS polymorphisms and breast cancer outcomes. ${ }^{91}$

\section{CES2}

Carboxylesterase 2 is one of the 3 enzymes responsible for converting capecitabine to 5-FU. In a study of 135 patients with breast cancer, the $\mathrm{CES} 2-832 \mathrm{C}>\mathrm{G}$ polymorphism was associated with a significantly enhanced response to capecitabine. It was also associated with an increased time to progression as compared with patients with wild-type CES2. ${ }^{92}$

\section{Dihydropyrimidine dehydrogenase (DPYD)}

Complete or partial DPYD deficiency results in severe 5-FU toxicity in approximately $3 \%-5 \%$ of individuals. Although at least 20 functional DPYD variants have been described, the DPYD*2A splice site variant is assumed to be the most common. ${ }^{6,93}$

\section{Platinum}

Platinum induces interstrand DNA cross-linking, leading to the cessation of DNA synthesis, cellular apoptosis, and toxicity. Platinum is modulated by proteins involved in DNA repair (ERCC1, ERCC2, and XRCC1), DNA detoxification (GSTP1 and MPO), and DNA transport (SLC31A1, ABCC2, and $\mathrm{ABCG} 2)^{5,6,93}$

To date, no genetic polymorphisms that specifically affect platinum metabolism or response have been identified. In a randomized trial of carboplatin and a taxane in patients with ovarian cancer, genetic polymorphisms in proteins of the platinum pathway (ABCC2, ABCG2, ERCC1, ERCC2, GSTP1, MPO, and XRCC1) were not significantly associated with clinical outcomes or toxicity. ${ }^{5,6,62}$ Moreover, most studies related to platinum pharmacogenetics have been performed on patients with non-small cell lung cancer. 


\section{Related SNPs}

\section{GSTMI and METIF}

A recent study of 85 patients with breast cancer being treated with a combination of cisplatin, cyclophosphamide, and carmustine demonstrated that patients with a gene deletion of GSTM1 had an increased median survival time. However, it was not possible to determine whether the effect was related to cisplatin, carmustine, or both. Patients who carried the MET1F G-7T polymorphism had a lower concentration of platinum 72 hours after administration and shorter survival. ${ }^{76}$

\section{$\mathrm{ERCCl}$}

As noted earlier, most studies of polymorphisms related to platinum therapy have been performed in patients with non-small cell lung cancer, a few of which are worth mentioning here due to their potential relevance to breast cancer. In a study of 62 patients with non-small cell lung cancer that were being treated with docetaxel and cisplatin, there was an association between the synonymous $\mathrm{N} 118 \mathrm{~N}$ polymorphism in ERCC and median survival time and time to progression. ${ }^{94}$ Similar results were found in another study involving 109 patients that were treated with cisplatin combination therapy, in which the ERCC1 N118N was significantly associated with overall survival. However, no association between ERCC1 N118N and ERCC2 polymorphisms were demonstrated in 8 separate studies, one of which involved 65 patients receiving gemcitabine and cisplatin therapy ${ }^{63,95}$ Thus, the relationship between ERCC polymorphisms and response to cisplatin remains uncertain.

\section{Anthracyclines}

The anthracyclines, which include doxorubicin and epirubicin, exhibit extremely variable $\mathrm{PK}$ among patients. This may be due to the fact that anthracyclines interact with a complex array of pathways involving various metabolizing enzymes and transporters. ${ }^{5}$

Carbonyl reductases (CBR1, CBR3) and aldoketoreductases (AKR1A1, AKR1C2) are responsible for converting doxorubicin and epirubicin via phase 2 reduction reactions to doxorubicinol and epirubicinol, respectively, which are then inactivated by CYP3A4 and CYP3A5. Efflux is mediated by $\mathrm{ABCB} 1, \mathrm{ABCC} 1, \mathrm{ABCC} 2$, and $\mathrm{ABCG} 2$ transporters. ${ }^{5}$ Epirubicin also undergoes phase 2 reactions by conjugation, mostly via UGT2B7. Orphan nuclear receptors are involved in regulating the transcription of many of the CYP enzymes and transporters of the anthracycline pathway and may contribute as well to variability. ${ }^{5,53} A B C B 1$, which encodes P-glycoprotein, a well-known ATP-binding cassette transporter, has been associated with drug resistance. The most common ABCB1 SNPs are 1236C $>$ T, 2677G $>$ T/A, and $3435 \mathrm{C}>\mathrm{T}$, which appear to disrupt $\mathrm{ABCB} 1$ substrate transport. ${ }^{5}$

Several genes have been identified that may be involved in anthracycline-mediated killing of tumor cells. For instance, glutathione s-transferases (GSTs) are involved in the catalysis of secondary organic oxidation products formed by chemotherapy. These products can cause additional cellular injury; thus, individuals who lack GST may have better responses to anthracyclines. ${ }^{5}$

The anthracyclines have been used for many years; however, the genetic basis of interpatient variability remains unclear. Large, prospective clinical studies are needed to determine the genetic predictors that may contribute to variations in anthracycline response. ${ }^{5}$

\section{Related SNPs}

\section{CBRI and CBR3}

CBR1 and CBR3 function as phase 1 metabolizers of doxorubicin. Doxorubicin is metabolized to the inactive metabolite doxorubicinol, which has been implicated in doxorubicin cardiotoxicity. Recently, the CBR3 11G $>$ A polymorphism was linked to increased tumor reduction and hematologic toxicity in 101 southwest Asian patients with breast cancer. CBR3 $11 \mathrm{G}>\mathrm{A}$ is associated with decreased conversion of doxorubicin to doxorubicinol, whereas $\mathrm{CBR} 3730 \mathrm{G}>\mathrm{A}$ is associated with increased conversion of doxorubicin to doxorubicinol. ${ }^{96}$

\section{$A B C B I$ and $A B C G 2$}

The ATP-binding cassette transporters ABCB1 and ABCG2 have been well characterized in terms of polymorphisms and doxorubicin PK. Although no association has been documented between ABCG2 421C $>\mathrm{A}$ and doxorubicin $\mathrm{PK}, 3$ common ABCB1 polymorphisms, 1236C $>\mathrm{T}$, $2677 \mathrm{G}>\mathrm{A} / \mathrm{T}, 3435 \mathrm{C}>\mathrm{T}$, were associated with doxorubicin clearance in a recent study of 62 Asian patients with breast cancer. ${ }^{97}$ Another study examining 68 patients being treated with anthracycline or combination anthracycline/ taxane therapy also found an association between the 3435T variant and better clinical response. ${ }^{98} \mathrm{~A}$ more recent study of 41 Brazilian women, however, failed to demonstrate a similar link. ${ }^{99}$

\section{SLC22A 16}

SLC22A16 is an anthracycline influx transporter. In a study of 62 Asian patients with breast cancer, a SLC22A16 poly- 
morphism, 146A $>\mathrm{G}$, was linked to increased exposure to doxorubicin and doxorubicinol. The clinical impact of this finding as it relates to doxorubicin response and toxicity was not determined, and remains to be elucidated. ${ }^{97}$

It is important to note that most of the studies mentioned above were carried out in Asian populations. Therefore, the $\mathrm{PG}$ of anthracycline response in non-Asian populations is unclear. It is also important to note that there are significant variations in allele frequencies among various populations. For instance, SLC22A16 146A $>$ G occurs at a much higher frequency in Asian populations (13\%-18\%) as compared to Caucasians (9\%). ${ }^{100,101}$ These types of variations need to be considered when validating PG approaches in different populations.

\section{UGT2B7}

UGT2B7 is the enzyme responsible for glucuronidation of epirubicin. Polymorphisms of UGT2B7 have been identified, but do not appear to be associated with any changes in rate of glucuronidation of epirubicin. ${ }^{102}$

\section{NQOI}

The NQO1 556C $>$ T and the NQO1*2 alleles have been shown to predict survival outcomes in patients with breast cancer and also predict response to epirubicin in breast carcinoma cells in vitro. ${ }^{103} \mathrm{~A}$ more recent study, however, failed to corroborate these results, ${ }^{104}$ leaving the role of these variations in question.

\section{Targeted therapy}

\section{Trastuzumab/lapatinib/bevacizumab}

Targeted therapeutics, including anti-HER2 antibodies (trastuzumab and lapatinib) and bevacizumab, an antiangiogenic agent directed against vascular endothelial growth factor (VEGF), are approved treatments for advanced breast cancers and are currently in clinical trials for early-stage breast cancer. Although both trastuzumab and lapatinib inhibit the same receptor, ErbB2, using the 2 drugs in combination is a potentially attractive option because each agent targets a different part of the receptor; trastuzumab targets the extracellular domain, and lapatinib targets the intracellular domain. In addition, the drugs appear to have different mechanisms of action; trastuzumab increases internalization and degradation of ErbB2, whereas lapatinib inhibits ErbB2 tyrosine kinase activity. ${ }^{105}$

The majority of breast cancers are responsive to estrogen, but upon progression of the disease, other growth-promoting pathways are activated, including the ErbB receptor signaling system. The ErbB/HER family of epithelial growth factor receptors (EGFRs) is composed of 4 members that share a high degree of sequence homology: EGFR (ErbB1, HER1), ErbB2 (HER2), ErbB3 (HER3), and ErbB4 (HER 4). ${ }^{106,107}$ The prototypical member of this family, EGFR, is a transmembrane protein consisting of an extracellular binding domain, a hydrophobic transmembrane domain, and a cytoplasmic tyrosine kinase domain. ${ }^{105}$ ErbB2 is commonly overexpressed in breast cancer cells. It is this overexpressed ErbB2 that is the major target for both trastuzumab and lapatinib. ${ }^{108}$ The binding of trastuzumab to its target on the extracellular domain of ErbB2 may be affected by differential amino acid expression and functional polymorphisms in this region of the receptor and may influence individual drug responses. ${ }^{1}$ It has also been suggested that lapatinib PK may be altered in individuals carrying polymorphisms in the gene coding for hepatic CYP2C19 or P-glycoprotein. ${ }^{108}$

\section{Related SNPs}

Fc- $\gamma$ receptor

In 2008, Musolino et $\mathrm{al}^{109}$ investigated $\mathrm{Fc}-\gamma$ receptor polymorphisms and their association with the clinical efficacy of trastuzumab-based therapy for HER2-positive (HER+) patients with breast cancer. Fc- $\gamma$ polymorphisms have been shown to affect antibody-dependent cell-mediated cytotoxicity responses of natural killer cells and monocytes. The investigators identified 2 polymorphisms, Fc- $\gamma$ RIIIA-158 $\mathrm{V} / \mathrm{V}$ and $\mathrm{Fc}-\gamma \mathrm{RIIa}-131 \mathrm{H} / \mathrm{H}$ that were significantly associated with objective response rate and progression-free survival. The $\mathrm{H} / \mathrm{H}$ and $\mathrm{V} / \mathrm{V}$ genotypes were also associated with higher trastuzumab-mediated cytotoxicity in peripheral blood mononuclear cells as compared with other genotypes. These results underscore the need for additional studies of the role of Fc- $\gamma$ receptor polymorphisms on clinical outcomes with trastuzumab therapy. ${ }^{108}$

\section{Future applications of PG}

The US Food and Drug Administration (FDA) recently approved a DNA microarray-based pharmacogenetics test for CYP2D6 polymorphisms (AmpliChip CYP450 test). This test can detect 27 different CYP2D6 variants, including nonfunctional variants (CYP2D6*3, CYP2D6*4, CYP2D6*5, and CYP2D6*6), deficient variants commonly found in Asians and black Africans (CYP2D6*10 and CYP2D6*17), and ultra-rapid variants found in Middle Easterners and Ethiopians (CYP2D6*2XN). ${ }^{109}$ A label change has been proposed to introduce the possibility of testing for CYP2D6 polymorphisms prior to tamoxifen use due to the known 
increase in breast cancer recurrence in women with altered CYP2D6 metabolism. ${ }^{76}$ A final decision about testing is forthcoming. ${ }^{92}$

There is a prevalent belief among researchers and clinicians that PG approaches to cancer therapy (ie, personalized medicine) will be cost prohibitive, due to the current pharmaceutical blockbuster model, government regulation, a dysfunctional payment system, and physician behaviors. ${ }^{110}$ Studies that analyze the pharmacoeconomics of personalized medicine, including the cost effectiveness of using genetic information to inform drug choice and therapy regime, are strongly recommended. In addition, effective implementation of PG in the clinical setting will require active involvement of the FDA, including establishment of protocols or guidelines on how genetic information collected from the population should be handled or used. The gene signature of individual tumors might predict utility of specific treatment regimens in individual patients with breast cancer. ${ }^{111}$

\section{Ethics of PG}

The fact that PG requires the collection of specific genetic information, and in some cases, the sequence of the patient's complete genome, raises the question of who should have access to this information and how the use of this data should be regulated. ${ }^{112-115}$ In situations where a subject's genetic information has been collected as part of a clinical diagnosis, the individual may have a strong interest in keeping the information confidential, even though others may believe that they have a claim to the information. For example, family members who are genetically related may want to know the results of genetic studies. Third-party health insurance providers may claim to have a right to the information if they are to accurately assess the risk they are taking on by insuring the patient. Employers may wish to have access to the information as well since they will bear the majority of the cost of insuring the individual. It has been speculated that the reluctance of individuals to undergo certain forms of genetic testing today is driven by a fear of losing their job, their health insurance, or both. In other words, people believe that by submitting to such tests, they in essence give up certain rights. ${ }^{112,113}$

Another ethical issue involved in $\mathrm{PG}$ is cost. ${ }^{116} \mathrm{~A}$ point of general consensus within the pharmaceutical sector is that the cost of genetically tailored drugs is likely to be high. This is because major research must be carried out to identify the genetic profiles that will make personalized medicine possible, followed by expensive and time-consuming research to test existing and novel drugs in the context of particular genetic profiles. Given that these costly therapies, should they emerge, might be accessible to only a limited segment of the general population, it remains unclear whether pharmaceutical companies would be willing to invest in such research. There is the possibility that because of the potentially small financial gain from this novel approach to medicine, pharmaceutical companies will be less inclined to engage in the effort to make personalized medicine a reality. ${ }^{117}$

Subjects who are pharmacogenomically classified as nonresponsive to drug treatment may carry with them a stigma of rejection, particularly by private insurance companies. This may bring about a personal economic crisis and could also result in psychological issues for people or communities as the idea of being "untreatable" becomes more widespread.

Finally, as mentioned above, it is widely expected that PG therapies will be more expensive than current regimes, and the resulting premium drug prices may make these new therapies inaccessible to those who are struggling economically. Additional questions, such as will insurance companies pay for more expensive PG therapies or for the tests needed to prescribe them, and if so, will the benefits of PG be available only to those who are able to pay for them "out-of-pocket," must be addressed as PG becomes more commonplace in the clinical setting. A very important act for future progress in that regard is the Nondiscrimination Act (GINA) passed by the congress in 2008 to minimize the risk of exploitation by insurers and other interested parties of personal genetic data.

\section{Conclusion}

PG is a discipline that is rapidly moving beyond the study of a single gene, to a comprehensive analysis of entire pathways that integrates aspects of PK and PD studies. The possibility of therapy-based knowledge of how the patient will best respond will soon be possible through the clinical application of PG. However, in order to reach this goal of individualized intervention, clinical and epidemiologic studies are urgently needed to assess (1) how drug response varies among individuals with different genotypes, (2) the prevalence of relevant genotypes in the population and in specific subpopulations, and (3) the degree to which environmental factors (such as other drugs and diet) interact with genetic factors to influence drug response. Both clinical trials and observational epidemiologic studies are 
crucial for generating the population-based data needed to apply PG to the practice of medicine and public health in the 21 st century. The promise of PG studies is dramatic improvements in drug safety and efficacy, thereby transforming patient care from a one-drug-fits-all approach into customized therapy.

\section{Disclosure}

The authors report no conflicts of interest in this work.

\section{References}

1. Milanezi F, Carvalho S, Schmitt FC. EGFR/HER2 in breast cancer: a biological approach for molecular diagnosis and therapy. Expert Rev Mol Diagn. 2008;8(4):417-434.

2. O'Brien C, Cavet G, Pandita A, et al. Functional genomics identifies ABCC3 as a mediator of taxane resistance in HER2-amplified breast cancer. Cancer Res. 2008;68(13):5380-5389.

3. Jemal A, et al. Cancer Statistics, 2009. CA Cancer J Clin. 2009;59: 225-249.

4. Rebbeck TRT, Troxel AB, Norman S, et al. Pharmacogenetic modulation of combined hormone replacement therapy by progesteronemetabolism genotypes in postmenopausal breast cancer risk. Am J Epidemiol. 2007;166(12):1392-1399.

5. Tan SH, Lee SC, Goh BC, Wong J. Pharmacogenetics in breast cancer therapy. Clin Cancer Res. 2008;14(24):8027-8041.

6. Huang RS, Ratain MJ. Pharmacogenetics and pharmacogenomics of anticancer agents. CA Cancer J Clin. 2009;59(1):42-55.

7. Evans WE, McLeod HL. Pharmacogenomics - drug disposition, drug targets, and side effects. N Engl J Med. 2003;348(6):538-549.

8. Zhang W, Huang RS, Dolan ME. Integrating epigenomics into pharmacogenomics studies. Pharmacogenomics Pers Med. 2008;1:7-14.

9. Ingle JN. Pharmacogenomics of tamoxifen and aromatase inhibitors. Cancer. 2008;112 Suppl 3:695-699.

10. Weinshilboum R. Pharmacogenomics of endocrine therapy in breast cancer. Adv Exp Med Biol. 2008;630:220-231.

11. Gradhand UK, Kim RB. Pharmacogenomics of MRP transporters (ABCC1-5) and BCRP (ABCG2). Drug Metab Rev. 2008;40(2): 317-354.

12. Kim S, Misra A. SNP genotyping: technologies and biomedical applications. Annu Rev Biomed Eng. 2007;9:289-320.

13. Shimizu C, Fujiwara Y. Personalized systemic treatment for breast cancer patients: is it a reality? Breast Cancer. 2008;15(2): 141-144.

14. Blackhall FH, Howell S, Newman B. Pharmacogenetics in the management of breast cancer - prospects for individualised treatment. Fam Cancer. 2006;5(2):151-157.

15. Lymberis SC, Parhar PK, Katsoulakis E, Formenti SC. Pharmacogenomics and breast cancer. Pharmacogenomics. 2004;5(1):31-55.

16. Sims-Mourtada J, Izzo JG, Ajani J, Chao KS. Sonic hedgehog promotes multiple drug resistance by regulation of drug transport. Oncogene. 2007;26 (38):P5674-P5679.

17. Brauch H, et al. Pharmacogenomics of tamoxifen therapy. Clin Chem. 2009;55(10):1770-1782.

18. Briest S, Stearns V. Tamoxifen metabolism and its effect on endocrine treatment of breast cancer. Clin Adv Hematol Oncol. 2009;7(3):185-192.

19. Goetz MP, Kamal A, Ames MM. Tamoxifen pharmacogenomics: the role of CYP2D6 as a predictor of drug response. Clin Pharmacol Ther. 2008;83(1):160-166.

20. Stearns V, Johnson MD, Rae JM, et al. Active tamoxifen metabolite plasma concentrations after coadministration of tamoxifen and the selective serotonin reuptake inhibitor paroxetine. J Natl Cancer Inst. 2003;95(23):1758-1764.
21. Schroth W, Antoniadou L, Fritz P, et al. Breast cancer treatment outcome with adjuvant tamoxifen relative to patient CYP2D6 and CYP2C19 genotypes. J Clin Oncol. 2007;25(33):5187-5193.

22. Amirimani B, et al. Increased transcriptional activity of the CYP3A4*1B promoter variant. Environ Mol Mutagen. 2003;42(4):299-305.

23. Hustert E, et al. The genetic determinants of the CYP3A5 polymorphism. Pharmacogenetics. 2001;11(9):773-779.

24. Kuehl P, et al. Sequence diversity in CYP3A promoters and characterization of the genetic basis of polymorphic CYP3A5 expression. Nat Genet. 2001;27(4):383-391.

25. Goetz MP, et al. Pharmacogenetics of tamoxifen biotransformation is associated with clinical outcomes of efficacy and hot flashes. J Clin Oncol. 2005;23(36):9312-9318.

26. Jin Y, et al. CYP2D6 genotype, antidepressant use, and tamoxifen metabolism during adjuvant breast cancer treatment. J Natl Cancer Inst. 2005;97(1):30-39.

27. Tucker AN, et al. Polymorphisms in cytochrome P4503A5 (CYP3A5) may be associated with race and tumor characteristics, but not metabolism and side effects of tamoxifen in breast cancer patients. Cancer Lett. 2005;217(1):61-72.

28. Wegman P, et al. Genetic variants of CYP3A5, CYP2D6, SULT1A1, UGT2B15 and tamoxifen response in postmenopausal patients with breast cancer. Breast Cancer Res. 2007;9(1):R7.

29. Nagar S, Walther S, Blanchard RL. Sulfotransferase (SULT) 1A1 polymorphic variants $* 1, * 2$, and $* 3$ are associated with altered enzymatic activity, cellular phenotype, and protein degradation. Mol Pharmacol. 2006;69(6):2084-2092.

30. Ohtake E, et al. Frequency distribution of phenol sulfotransferase 1A1 activity in platelet cells from healthy Japanese subjects. Eur J Pharm Sci. 2006;28(4):272-277.

31. Raftogianis RB, et al. Phenol sulfotransferase pharmacogenetics in humans: association of common SULT1A1 alleles with TS PST phenotype. Biochem Biophys Res Commun. 1997;239(1):298-304.

32. Nowell S, et al. Association between sulfotransferase 1A1 genotype and survival of breast cancer patients receiving tamoxifen therapy. J Natl Cancer Inst. 2002;94(21):1635-1640.

33. Wegman P, et al. Genotype of metabolic enzymes and the benefit of tamoxifen in postmenopausal breast cancer patients. Breast Cancer Res. 2005;7(3):R284-R290.

34. Hebbring SJ, Adjei AA, Baer JL, et al. Human SULT1A1 gene: copy number differences and functional implications. Hum Mol Genet. 2007; $16(5): 463-470$.

35. Nowell SA, et al. Association of genetic variation in tamoxifenmetabolizing enzymes with overall survival and recurrence of disease in breast cancer patients. Breast Cancer Res Treat. 2005;91(3): 249-258.

36. Goetz MP, et al. The impact of cytochrome P450 2D6 metabolism in women receiving adjuvant tamoxifen. Breast Cancer Res Treat. 2007; 101(1):113-121.

37. Goetz MP, Kamal A, Ames MM. Tamoxifen pharmacogenomics: the role of CYP2D6 as a predictor of drug response. Clin Pharmacol Ther. 2008;83(1):160-166.

38. Gallacchi P, et al. Increased expression of estrogen-receptor exon5 -deletion variant in relapse tissues of human breast cancer. Int $J$ Cancer. 1998;79(1):44-48.

39. Jirstrom K, et al. Adverse effect of adjuvant tamoxifen in premenopausal breast cancer with cyclin D1 gene amplification. Cancer Res. 2005; 65(17):8009-8016.

40. Bostner J, et al. Amplification of CCND1 and PAK1 as predictors of recurrence and tamoxifen resistance in postmenopausal breast cancer. Oncogene. 2007;26(49):6997-7005.

41. Lundgren K, et al. Gene products of chromosome 11q and their association with CCND1 gene amplification and tamoxifen resistance in premenopausal breast cancer. Breast Cancer Res. 2008;10(5):R81.

42. Wegman P, et al. p53 polymorphic variants at codon 72 and the outcome of therapy in randomized breast cancer patients. Pharmacogenet Genomics. 2006;16(5):347-351. 
43. Kim HS, et al. Overexpression of p53 is correlated with poor outcome in premenopausal women with breast cancer treated with tamoxifen after chemotherapy. Breast Cancer Res Treat. 2009;121(3):777-788.

44. Hadji P, et al. Practical guidance for the management of aromatase inhibitor-associated bone loss. Ann Oncol. 2008;19(8):1407-1416.

45. Yamamoto DS, Viale PH. Update on identifying and managing osteoporosis in women with breast cancer. Clin J Oncol Nurs. 2009;13(5): E18-E29.

46. Hiscox S, Davies EL, Barrett-Lee P. Aromatase inhibitors in breast cancer. Maturitas. 2009;63(4):275-279.

47. Ma CX, et al. Human aromatase: gene resequencing and functional genomics. Cancer Res. 2005;65(23):11071-11082.

48. Colomer R, et al. A single-nucleotide polymorphism in the aromatase gene is associated with the efficacy of the aromatase inhibitor letrozole in advanced breast carcinoma. Clin Cancer Res. 2008;14(3):811-816.

49. Lopez-Guerrero JA, Garcia-Casado Z, Guerrero-Zotano AL, et al. Corroboration of polymorphisms in the aromatase (CYP19A1) gene with response to neo-adjuvant therapy with letrozole in postmenopausal women with stages II-II ER/PgR-positive breast cancer. Proc Am Soc Clin Oncol. 2007;25:602.

50. Riancho JA, et al. Aromatase gene and osteoporosis: relationship of ten polymorphic loci with bone mineral density. Bone. 2005;36(5): 917-925.

51. Marsh S, McLeod HL. Pharmacogenetics and oncology treatment for breast cancer. Expert Opin Pharmacother. 2007;8(2):P119-P127.

52. Zarrabeitia MT, et al. A common polymorphism in the $5^{\prime}$-untranslated region of the aromatase gene influences bone mass and fracture risk. Eur J Endocrinol. 2004;150(5):699-704.

53. Acharya CR, Hsu DS, Anders CK, et al. Gene expression signatures, clinicopathological features, and individualized therapy in breast cancer. JAMA. 2008;299(13):1574-1587.

54. Gligorov J, Lotz JP. Preclinical pharmacology of the taxanes: implications of the differences. Oncologist. 2004;9 Suppl 2:3-8.

55. Bruno R, et al. Alpha-1-acid glycoprotein as an independent predictor for treatment effects and a prognostic factor of survival in patients with non-small cell lung cancer treated with docetaxel. Clin Cancer Res. 2003;9(3):1077-1082.

56. Hansen JE, Larsen VA, Bog-Hansen TC. The microheterogeneity of alpha 1-acid glycoprotein in inflammatory lung disease, cancer of the lung and normal health. Clin Chim Acta. 1984;138(1):41-47.

57. Nakamura T, et al. Alpha 1-acid glycoprotein expression in human leukocytes: possible correlation between alpha 1-acid glycoprotein and inflammatory cytokines in rheumatoid arthritis. Inflammation. 1993; 17(1):33-45.

58. Iscan M, et al. The expression of cytochrome P450 enzymes in human breast tumours and normal breast tissue. Breast Cancer Res Treat. 2001; $70(1): 47-54$.

59. McFadyen MC, et al. Cytochrome P450 CYP1B1 over-expression in primary and metastatic ovarian cancer. Br J Cancer. 2001;85(2): 242-246.

60. McKay JA, et al. Expression of cytochrome P450 CYP1B1 in breast cancer. FEBS Lett. 1995;374(2):270-272.

61. Murray GI, et al. Tumor-specific expression of cytochrome P450 CYP1B1. Cancer Res. 1997;57(14):3026-3031.

62. Marsh S, Somlo G, Li X, et al. Pharmacogenetic analysis of paclitaxel transport and metabolism genes in breast cancer. Pharmacogenomics $J$. 2007;7(5):362-365.

63. Chang JC, et al. Gene expression patterns in formalin-fixed, paraffinembedded core biopsies predict docetaxel chemosensitivity in breast cancer patients. Breast Cancer Res Treat. 2008;108(2):233-240.

64. Isla D, et al. Single nucleotide polymorphisms and outcome in docetaxel-cisplatin-treated advanced non-small-cell lung cancer. Ann Oncol. 2004;15(8):1194-1203.

65. Mano M. Vinorelbine in the management of breast cancer: new perspectives, revived role in the era of targeted therapy. Cancer Treat Rev. 2006;32(2):106-118.
66. Pan JH, et al. MDR1 single nucleotide polymorphisms predict response to vinorelbine-based chemotherapy in patients with non-small cell lung cancer. Respiration. 2008;75(4):380-385.

67. Pan JH, et al. CYP450 polymorphisms predict clinic outcomes to vinorelbine-based chemotherapy in patients with non-small-cell lung cancer. Acta Oncol. 2007;46(3):361-366.

68. Wong $\mathrm{M}$, et al. Predictors of vinorelbine pharmacokinetics and pharmacodynamics in patients with cancer. J Clin Oncol. 2006;24(16): 2448-2455.

69. Schott AF, et al. Combination vinorelbine and capecitabine for metastatic breast cancer using a non-body surface area dosing scheme. Cancer Chemother Pharmacol. 2006;58(1):129-135.

70. de Jonge ME, et al. Clinical pharmacokinetics of cyclophosphamide. Clin Pharmacokinet. 2005;44(11):1135-1164.

71. Hassan M, et al. A mechanism-based pharmacokinetic-enzyme model for cyclophosphamide autoinduction in breast cancer patients. Br J Clin Pharmacol. 1999;48(5):669-677.

72. Gheuens E, Slee PH, de Bruijn EA. Bioavailability of cyclophosphamide in the CMF regimen. Onkologie. 1990;13(3):203-206.

73. Powis G, et al. Effect of body weight on the pharmacokinetics of cyclophosphamide in breast cancer patients. Cancer Chemother Pharmacol. 1987;20(3):219-222.

74. Pruthi S, et al. A multidisciplinary approach to the management of breast cancer, part 2: therapeutic considerations. Mayo Clin Proc. 2007;82(9): 1131-1140.

75. Su HI, et al. Association of cyclophosphamide drug-metabolizing enzyme polymorphisms and chemotherapy-related ovarian failure in breast cancer survivors. Fertil Steril. 2009;94(2):645-654.

76. Petros WP, et al. Associations between drug metabolism genotype, chemotherapy pharmacokinetics, and overall survival in patients with breast cancer. J Clin Oncol. 2005;23(25):6117-6125.

77. van Schaik RH. Cancer treatment and pharmacogenetics of cytochrome P450 enzymes. Invest New Drugs. 2005;23(6):513-522.

78. Nakajima M, et al. Genetic polymorphisms of CYP2B6 affect the pharmacokinetics/pharmacodynamics of cyclophosphamide in Japanese cancer patients. Pharmacogenet Genomics. 2007;17(6): $431-445$.

79. Ekhart $\mathrm{C}$, et al. Influence of polymorphisms of drug metabolizing enzymes (CYP2B6, CYP2C9, CYP2C19, CYP3A4, CYP3A5, GSTA1, GSTP1, ALDH1A1 and ALDH3A1) on the pharmacokinetics of cyclophosphamide and 4-hydroxycyclophosphamide. Pharmacogenet Genomics. 2008;18(6):515-523.

80. Heinemann V, et al. Comparison of the cellular pharmacokinetics and toxicity of $2^{\prime}, 2^{\prime}$-difluorodeoxycytidine and 1-betaD-arabinofuranosylcytosine. Cancer Res. 1988;48(14):4024-4031.

81. Plunkett W, Huang P, Gandhi V. Preclinical characteristics of gemcitabine. Anticancer Drugs. 1995;6 Suppl 6:7-13.

82. Sugiyama E, et al. Pharmacokinetics of gemcitabine in Japanese cancer patients: the impact of a cytidine deaminase polymorphism. J Clin Oncol. 2007;25(1):32-42.

83. Fukunaga AK, et al. Identification and analysis of single-nucleotide polymorphisms in the gemcitabine pharmacologic pathway. Pharmacogenomics J. 2004;4(5):307-314.

84. Rha SY, et al. An association between RRM1 haplotype and gemcitabine-induced neutropenia in breast cancer patients. Oncologist. 2007;12(6):622-630.

85. Yeo AW, Soong RC, Schuah BY, et al. Correlation of RRM1 promoter region single nucleotide polymorphisms (SNPs) with response and outcome in breast cancer patients treated with gemcitabine-based chemotherapy [abstract 14513]. J Clin Oncol. 2008;26.

86. Lamba JK, et al. Pharmacogenetics of deoxycytidine kinase: identification and characterization of novel genetic variants. J Pharmacol Exp Ther. 2007;323(3):935-945.

87. Nishiyama ME, Eguchi H. Pharmacokinetics and pharmacogenomics in gastric cancer chemotherapy. Adv Drug Deliv Rev. 2008;61(5):402-407. 
88. Martin DN, et al. Association of MTHFR gene polymorphisms with breast cancer survival. BMC Cancer. 2006;6:257.

89. Shrubsole MJ, et al. MTHFR genotypes and breast cancer survival after surgery and chemotherapy: a report from the Shanghai Breast Cancer Study. Breast Cancer Res Treat. 2005;91(1):73-79.

90. Watters JW, McLeod HL. Cancer pharmacogenomics: current and future applications. Biochim Biophys Acta. 2003;1603(2): 99-111.

91. Pare L, et al. Influence of thymidylate synthase and methylenetetrahydrofolate reductase gene polymorphisms on the disease-free survival of breast cancer patients receiving adjuvant 5 -fluorouracil/methotrexatebased therapy. Anticancer Drugs. 2007;18(7):821-825.

92. Ribelles $\mathrm{N}$, et al. A carboxylesterase 2 gene polymorphism as predictor of capecitabine on response and time to progression. Curr Drug Metab. 2008;9(4):336-343.

93. Tordai AW, Wang J, Andre F, et al. Evaluation of biological pathways involved in chemotherapy response in breast cancer. Breast Cancer Res. 2008;10(2):R37.

94. Ryu JS, et al. Association between polymorphisms of ERCC1 and XPD and survival in non-small-cell lung cancer patients treated with cisplatin combination chemotherapy. Lung Cancer. 2004;44(3):311-316.

95. Tibaldi C, et al. Correlation of CDA, ERCC1, and XPD polymorphisms with response and survival in gemcitabine/cisplatin-treated advanced non-small cell lung cancer patients. Clin Cancer Res. 2008;14(6): 1797-1803.

96. Fan L, et al. Genotype of human carbonyl reductase CBR3 correlates with doxorubicin disposition and toxicity. Pharmacogenet Genomics. 2008; 18(7):621-631.

97. Lal S, et al. Influence of ABCB1 and ABCG2 polymorphisms on doxorubicin disposition in Asian breast cancer patients. Cancer Sci. 2008;99(4):816-823.

98. Kafka A, et al. Polymorphism C3435T of the MDR-1 gene predicts response to preoperative chemotherapy in locally advanced breast cancer. Int J Oncol. 2003;22(5):1117-1121.

99. Rodrigues FF, et al. Correlation of polymorphism C3435T of the MDR-1 gene and the response of primary chemotherapy in women with locally advanced breast cancer. Genet Mol Res. 2008;7(1):177-183.

100. Engen RM, et al. Ethnic differences in pharmacogenetically relevant genes. Curr Drug Targets. 2006;7(12):1641-1648.

101. Lal S, et al. Novel SLC22A16 polymorphisms and influence on doxorubicin pharmacokinetics in Asian breast cancer patients. Pharmacogenomics. 2007;8(6):567-575.

102. Innocenti $F$, et al. Epirubicin glucuronidation is catalyzed by human UDP-glucuronosyltransferase 2B7. Drug Metab Dispos. 2001;29(5): 686-692.
103. Fagerholm R, et al. NAD(P)H:quinone oxidoreductase $1 \mathrm{NQO} 1 * 2$ genotype (P187S) is a strong prognostic and predictive factor in breast cancer. Nat Genet. 2008;40(7):844-853.

104. Hubackova M, et al. NAD(P)H:quinone oxidoreductase 1 Pro187Ser polymorphism and expression do not cosegregate with clinicopathological characteristics of human mammary tumors. Pharmacogenet Genomics. 2009;19(7):505-512.

105. Heist RS, Christiani D. EGFR-targeted therapies in lung cancer: predictors of response and toxicity. Pharmacogenomics. 2009;10(1): $59-68$.

106. Jin Q, Esteva FJ. Cross-talk between the ErbB/HER family and the type I insulin-like growth factor receptor signaling pathway in breast cancer. J Mammary Gland Biol Neoplasia. 2008;13(4):485-498.

107. Payne RE, Yague E, Slade MJ, et al. Measurements of EGFR expression on circulating tumor cells are reproducible over time in metastatic breast cancer patients. Pharmacogenomics. 2009;10(1):51-57.

108. Benusiglio PR. Focus on ERBB2. Pharmacogenomics. 2008; 9(7):825-828.

109. Musolino A, et al. Immunoglobulin $G$ fragment $C$ receptor polymorphisms and clinical efficacy of trastuzumab-based therapy in patients with HER-2/neu-positive metastatic breast cancer. J Clin Oncol. 2008;26(11):1789-1796.

110. Aspinall MG, Hamermesh RG. Realizing the promise of personalized medicine. Harv Bus Rev. 2007;85(10):108-117, 165.

111. Glinsky GV, Higashiyama T, Glinskii AB. Classification of human breast cancer using gene expression profiling as a component of the survival predictor algorithm. Clin Cancer Res. 2004;10(7):2272-2283.

112. Sillon G, Joly Y, Feldman S, Avard D. An ethical and legal overview of pharmacogenomics: perspectives and issues. Med Law. 2008;27(4): 843-857.

113. Lee SS, Mudaliar A. Medicine. Racing forward: the Genomics and Personalized Medicine Act. Science. 2009;323(5912):342.

114. Pendergast MK. Regulatory agency consideration of pharmacogenomics. Exp Biol Med (Maywood). 2008;233(12):1498-1503.

115. Nyika A. Ethical and practical challenges surrounding genetic and genomic research in developing countries. Acta Tro. 2009;112 Suppl 1: S21-S31.

116. Meckley LM, Gudgeon JM, Anderson JL, Williams MS, Veenstra DL. A policy model to evaluate the benefits, risks and costs of warfarin pharmacogenomic testing. Pharmacoeconomics. 2010;28(1):61-74.

117. Kirk RJ, Hung JL, Horner SR, Perez JT. Implications of pharmacogenomics for drug development. Exp Biol Med (Maywood). 2008; 233(12):1484-1497.
Pharmacogenomics and Personalized Medicine

\section{Publish your work in this journal}

Pharmacogenomics and Personalized Medicine is an international, peerreviewed, open access journal characterizing the influence of genotype on pharmacology leading to the development of personalized treatment programs and individualized drug selection for improved safety, efficacy and sustainability. This journal is indexed on the American Chemical

\section{Dovepress}

Society's Chemical Abstracts Service (CAS). The manuscript management system is completely online and includes a very quick and fair peer-review system, which is all easy to use. Visit http://www.dovepress. $\mathrm{com} /$ testimonials.php to read real quotes from published authors. 